\title{
Business Process Modeling Linguistic Approach - Problems of Business Strategy Design
}

\author{
Jozef Stasak $^{1, *}$, Radka Vanickova ${ }^{1}$, Michal Grell ${ }^{2}$ \\ ${ }^{1}$ Institute of Technology and Business in Ceske Budejovice, Czech \\ ${ }^{2}$ Civil Association Education-Science-Research, Slovak Republic
}

Copyright $(\subset 2015$ by authors, all rights reserved. Authors agree that this article remains permanently open access under the terms of the Creative Commons Attribution License 4.0 International License

\begin{abstract}
This paper deals with problems related to Business Process Modeling Linguistic Approach - Problems of Business Strategy Design. The main goal of that paper is to prepare a proposal closely related to business strategy design in form of text written in a natural language and in form of linguistic sets, which contain appropriate linguistic variables regulated by rules of business process ontology principles and linguistic approach of business process modeling. A description of problems related to Balanced Scorecard (BSC) Business Strategy Design and to business process management and modeling - linguistic approach creates the paper's first part, while The Principle Business Process Linguistic Equation - PBPL Equation existence - together with assumptions, terms and principles related to its existence and functionality play a role of great importance there. Answering the question: how the principle business process linguistic equation may be applied in solution of business strategy design and business process management problems - business process ontology aspects?" It is a subject of the paper's second part. However, the problems of related works and contributions of the paper's content are considered to be the paper's final chapters as well.
\end{abstract}

Keywords Business Process Modeling, Linguistic Approach, Business Strategy Design

\section{Introduction}

A business mission statement and objectives create the principal basis for preparing of any business strategy goals. However, any business strategy goal is being presented via set of sentences written in a natural language (e.g. In English or any other language) and via set of numeric or alphanumeric information. In many cases a set of sentences in natural language and sets of numeric or alphanumeric information are interconnected very strongly and in different ways. In many cases, such sets are considered to be Strategy Goal Indicators (SGI -elements) and are strictly interconnected to core, support and management business processes. On the other hand, these interconnections usually are not of a deterministic nature and several uncertainties may be observed within and among them. We can say that business process ${ }^{1}$ management provided on strategic, tactic and operational level are often characterized by fuzziness. This term means, that the decision premises are not available in the form of mathematic models or numeric values, but rather as fuzzy conditions, such as "low processing time" or "high quality" as well.

Those aspects might be occurred here by extending process modeling through the consideration and processing of fuzziness using the fuzzy-set-theory. The fuzzy extension will be reproduced with the EPC ${ }^{2}$. The EPC was chosen as a process modeling language due to its popularity within modeling practice [19]. The same aspects are concerned to interconnection among sets, which contain SGI -elements and sets, which contain elements closely related to core, support and management processes too. However, in many cases, different type of images are applied in order to visualize the above mentioned SGI -elements, different types of business processes and interconnections among them, while there are natural language sentences (NLS) as well.

With respect to that issue, the following question may be postulated: "How the text and image semantic analysis systems may be applied in business process management and modeling problems?"

The main goal of that paper is to prepare a proposal closely related to business strategy design in form of text written in a natural language and in form of linguistic sets, which contain appropriate linguistic variables regulated by rules of business process ontology principles and linguistic approach of business process modeling. In order to achieve the above-mentioned main goal the following partial goals shall be postulated and fulfilled:

1 The terms process and business process are considered the same terms from semantic point of view

2 EPC - Event Process Control 
- To define the term of Linguistic sets, incl. assumptions for their and functionality

- To postulate The Principle Business Process Linguistic Equation - PBPL Equation incl. assumptions, terms and principles related to its existence and functionality.

- To postulate the PBPL Equation solutions for appropriate BSC System perspectives

However, the main goal determines the paper's structure as well, while a description of problems related to Balanced Scorecard (BSC) Business Strategy Design and to business process management and modeling - linguistic approach creates the paper's first part. The Principle Business Process Linguistic Equation - PBPL Equation existence - together with assumptions, terms and principles related to its existence and functionality play a role of great importance there.

Answering the question "How the Principle Business Process Linguistic Equation may be applied in solution of business strategy design and business process management problems - business process ontology aspects?" is a subject of the paper's second part. However, the problems of related works and contributions of the paper's content are considered to be the paper's final chapters as well.

\section{Balanced Scorecard System Business Strategy Design and Business Process Management Problems - Linguistic Approach - Theoretical Aspects}

\subsection{Terms and Principles}

The business process management passed through several phases and stages until achieved that content and form, which are valid at present. However, before getting started explanation individual aspects and problems closely related to business process management and modeling problems let us try explaining what the term process management is.

The business processes are running within any firm or company regardless its business mission statement or objectives. The term process management postulates the fact that no business process (BP) running in the firm or company must stay alone; it means for any business process shall exist the personality who is responsible for that process, while the personality may be considered to be: the $B P$ owner, the $B P$ administrator or the BP executor.

The terms business mission statement and business objectives are closely related to the term denoted as business strategy goals or aims, which may be quantified via set of strategic goal indicators (SGI(i). Hacklin, F.-Wallnoefer [6], introduce a strategy-as-practice perspective and to explore the implications and limitations of applying the business model as a strategizing device. Design/methodology/approach - a single-case study design was selected to explore the implications and limitations of using the business model as a strategizing device in a high-tech firm [6].

Findings - the business model - provide a valuable structural template for mapping the current business model of a firm. However, in developing and discussing strategic options, it acts more as a symbolic artefact stimulating a creative decision-making process than an analytic tool with a clear sequence of steps.

Practical implications - when working with the business model concept in practice, its technical and linguistic legitimacy is initially highly limited. In the process of gaining legitimacy, however, a collective lock-in to the current strategic identity may arise. Managers have to be aware of these limitations and need to achieve an appropriate balance within the organization Hacklin, F.- Wallnoefer, [6]. Yuksel, I, Dagdeviren, [21] postulated that the Balanced Scorecard (BSC) method suggests that business performance should be evaluated not only by using financial indicators but also simultaneously considering non-financial indicators. It has been revealed in the review of relevant literature that despite the satisfying levels achieved in conceptual and theoretical dimension of BSC, the method has some deficiencies in terms of implementation on a quantitative basis and that there remain some problems to be resolved subject of this study covered the measurement and evaluation dimension of BSC.

With respect to the above-mentioned facts and postulates, the BSC System might play a role not only closely related to the firm or company business performance evaluation tool; however it might be considered to be business model concept representative as well. In general, the BSC System consists of five perspectives: financial, customers, internal business process and learning and growth perspective, while one more perspective may be added to those perspectives as well. This perspective is denoted as technological perspective and is closely related to business technological support and with problems of governance and risk management too [5].

In order to achieve pre-defined business strategy goals or aims, a set of adequate business processes shall be running in the firm or company, while the business processes may be categorized as core $\left(\mathrm{Cp}^{\prime}\left(\mathrm{i}, \mathrm{j}^{\prime}\right)\right)$ support $\left(\mathrm{Sp}^{\prime}\left(\mathrm{i}, \mathrm{j}^{\prime}\right)\right)$ and management processes (Mp' $\left(i, j^{\prime}\right)$ ). On the other hand, there is a direct interconnection between business strategy goals or aims and business processes via BSC internal business processes perspective especially. These interconnections may be quantified via set of indicators denoted as success factors ${ }^{3}-\left[\left(\mathrm{p} 1\left(\mathrm{i}, \mathrm{j}^{\prime}\right),\left(\mathrm{p} 2\left(\mathrm{i}, \mathrm{j}^{\prime}\right), \ldots . .(\mathrm{p} 12(\mathrm{i}\right.\right.\right.$, $\left.\left.\mathrm{j}^{\prime}\right)\right]$. With respect to BPM methodology, any business process (BP) is being designed, implemented and operated in the firm or company in order to generate a set of appropriate outputs closely related to business strategy indicators, while

3 The term success factors is postulated within business process modeling methodology developed and established by Software A.G. - IdS Scheer Company - hereinafter BPM Methodology, which is considered to be a dominant scientific authority related to Business Process Management 
there are needed adequate inputs and business process functions, which enable transforming the inputs into adequate outputs as well.

On the other hand, any BP is represented by functional, process, data and organization view too [14]. However, any BP dynamics is represented by its own functionality, which shall be described in an appropriate way and that description creates an integral part of the firm or company business intellectual capital, which is closely related to BSC learning and growth perspective as well.

Calabrese, A.- Costa, R. -Menichini, T. proposes a model for Intellectual capital (IC) evaluation by integrating fuzzy logic and analytic hierarchy process (AHP). This fuzzy AHP approach allows capturing and fostering (IC) dynamics. Experts and managers are greatly supported by the use of linguistic variables in the evaluation process of the company intangible assets [4].

\subsection{Business strategy design in form of text written in a natural language and in form of fuzzy sets, which contain appropriate linguistic variables}

When considering a set of key performance indicator (KPI indicators) they might be postulated a set of logical sentences written in a natural language (TNL sentences), e.g. Ten percent Turnover increase or Five percent Production cost decrease. Both of the above-mentioned KPIs written in TNL language may be create elements of the $\{\mathrm{Sq}(\mathrm{i}, \mathrm{j})\}$ set, where those KPI logical sentences are being stored ( $i$ - number of logical sentence, $\quad \mathrm{j}=1$....m1 - index of words, which create content of that logical sentence, while the sentence "Ten percent Turnover increase" is considered to be $\mathrm{i}=1$ element and the sentence "Five percent Production cost decrease" is considered to be $\mathrm{i}=2$ element. Those logical TNL sentence elements might be transformed into $\{$ Sreq $(\mathrm{i}, \mathrm{j})\}$ set elements (linguistic variables), where the linguistic variables represent results of semantic analyses related to the above-mentioned TNL text logical sentences (see also Table 1).

Table 1. Set of primary strategic aims postulated in form of TNL sentences and in form of fuzzy sets, which contain appropriate linguistic variables

\begin{tabular}{|c|c|}
\hline $\begin{array}{c}\text { TNL (text written in natural } \\
\text { language) version }\end{array}$ & Linguistic variable version \\
\hline & \\
\hline $\begin{array}{c}\text { Ten percent Turnover increase, } \\
\text { weight eighty percent }\end{array}$ & $\begin{array}{c}\{\text { Sreq }(1,7)\}=\{[1],[\text { (turnover], } \\
{[\text { increase], [ten], [percent], }} \\
\text { [weight], [eighty], [percent] }\}\end{array}$ \\
\hline $\begin{array}{c}\text { Five percent Production cost } \\
\text { decrease, weight eighty percent }\end{array}$ & $\begin{array}{c}\{\text { Sreq }(2,7)\}=\{[\text { (costs], [decrease], } \\
\text { [five], [percent], [weight], [eighty], } \\
\text { [percent] }\}\end{array}$ \\
\hline
\end{tabular}

Furthermore, let us consider the sentence no. $1(\mathrm{i}=1)$ and let us compare it with BSC perspective formulation (see also Table 2) via KPI attributes, while the sixth attribute value is denoted by question mark, which corresponds to question "What about measures shall be done in order to fulfill that KPI value?

The BSC system consists of five perspectives postulated above. As a result of that, the MU1-weight attribute shall be decomposed into five partitions closely related to financial (MU1-FIN), customer's (MU1-CUS), internal BP (MU1-IBP), learning and growth (MU1-EAG) and technical perspective (MU1-TEC) as well.

Table 2. Example of predefined business strategy goal

\begin{tabular}{|c|c|c|c|c|c|}
\hline \multicolumn{5}{|c|}{ Key performance indicator (KPI) attributes } \\
\hline Name & Value & $\begin{array}{c}\text { Measure } \\
\text { unit } \\
\text { (MU1) }\end{array}$ & $\begin{array}{c}\text { MU1 - } \\
\text { weight }\end{array}$ & MU2 & Measures \\
\hline $\begin{array}{c}\text { Turnover } \\
\text { increase }\end{array}$ & ten & percent & eighty & percent & $(?)$ \\
\hline
\end{tabular}

The question (2.1) is "How the partitions values shall be calculated and what about relations do exist between those partitions and measures to be done by financial experts, customers, internal business process administrators (employees), and technology and employee know-how".

The question (2.2) "What about measures shall be done in order to achieve the business strategy goal predefined within Table 2?"is considered to be the sub ordinary one to the question postulated above.

The solutions leading to answering those questions will be postulated via considerations within Section 2.3 and 2.4

\subsection{The Principle Business Process Linguistic Equation - PBPL Equation - Assumptions, Terms and Principles}

Consideration no. 2.1 General overview

In general, the goal of any business process is to generate those outputs, which enable achieving pre-defined business strategy indicator values. In order to fulfill that requirement, the business process shall contain a set of appropriate functions, which are able to generate the above-mentioned outputs, while those functions represent elements creating the business process internal structure. On the other hand, the above-mentioned business process needs a set of appropriate inputs $\left\{\right.$ Petx $\left.\left(i, j^{\prime}\right)\right\}$, which might be of material, valuable and information nature. When the business processes $\{P(i, j)\}$ are acting to input set denoted as $\left\{\operatorname{Petx}\left(\mathrm{i}, \mathrm{j}^{\prime}\right)\right\}$, an intermediate product Res 1 ( $\mathrm{i}, \mathrm{j}$ ',') is being created, converted to intermediate product Res2 (i, j',') and subsequently decomposed to primary Tbex (i,j') business process outputs or products and to secondary business process outputs or products Retx (i, j','). With respect to the above-mentioned issues, the following principle equation (2.1), together with appropriate subordinated equations $(2.1 \mathrm{a}, 2.1 \mathrm{~b}$ and $2.1 \mathrm{c})$ might be postulated [13]:

$$
\begin{gathered}
\left\{\operatorname{Petx}\left(\mathrm{i}, \mathrm{j}^{\prime}\right)\right\} \otimes\{\mathrm{P}(\mathrm{i}, \mathrm{j})\}= \\
=\left\{\operatorname{Tbex}\left(\mathrm{i}, \mathrm{j},{ }^{\prime}\right)\right\} \otimes\left\{\operatorname{Retx}\left(\mathrm{i}, \mathrm{j}{ }^{\prime \prime}\right)\right\}
\end{gathered}
$$

$\left\{\operatorname{Petx}\left(\mathrm{i}, \mathrm{j}^{\prime}\right)\right\} \otimes\{\mathrm{P}(\mathrm{i}, \mathrm{j})\}=\left\{\operatorname{Res} 1\left(\mathrm{i}, \mathrm{j}{ }^{\prime},{ }^{\prime}\right)\right\}$

$\{\operatorname{Tbex}(i, j ')\} \otimes\{\operatorname{Retx}(i, j " \prime)\}=\{\operatorname{Res} 2(i, j, ', ')\}(2.1 b)$

$$
\left\{\operatorname{Res} 1\left(\mathrm{i}, \mathrm{j},{ }^{\prime \prime}\right)\right\}=\left\{\operatorname{Res} 2\left(\mathrm{i}, \mathrm{j},{ }^{\prime \prime}\right)\right\}
$$


$\{$ Petx (i, j') $\}$ - business process (BP) inputs $j^{\prime}=1 \ldots . . . m_{1}$ number of inputs for $i$-th business process

$\{\mathbf{P}(\mathbf{i}, \mathbf{j})\}$ - business process $\mathrm{j}=1 \ldots \mathrm{m}_{2}$ - number of business process functions for $i$-th business process

Res1 ( $\mathbf{i}, \mathbf{j}, ")$ - result of interaction related to inputs Petx and BP functions $-\mathrm{j} "{ }^{\prime \prime}=1 \ldots \mathrm{m}_{3}$ number of intermediate products created as a result of BP inputs Petx and BP functions interaction $\mathrm{i}$-th business process

$\operatorname{Res} 2(\mathbf{i}, \mathbf{j}, ")$ - j"' $=1 \ldots m_{3}$ number of intermediate products created as a result of BP inputs Petx and BP functions interaction i-th business process prepared for decomposition to primary Tbex outputs $(\mathrm{j})=1 \ldots \ldots \mathrm{m}_{4}$ number of primary products created as a result of BP inputs Petx and BP functions interaction for i-th business process) and secondary Retx outputs $(\mathrm{j})=1 \ldots . . \mathrm{m}_{4}$ number of primary products created as a result of BP inputs Petx and BP functions interaction for $\mathrm{i}$-th business process) In general, any business process may be described with use of many different methods, it means with use of different types of graphs or images, however that BP might be described with use of standard logical sentences written in a natural language (Slovak, English, German, etc.) - hereinafter known as TNL sentences.

The sets, the elements of which create linguistic variables and linguistic variable values are considered to be Linguistic sets (hereinafter known as $\mathrm{L}_{\mathrm{S}}$ sets). Any $\mathrm{L}_{\mathrm{S}}$ set consists of rows and columns, while any LS set row begins with so called leading element (denoted by $\mathrm{i}$-index $-\mathrm{i}=1 \ldots \ldots \mathrm{n}$ ) and standard elements $\quad$ Ls $(\mathrm{j})$, while $\mathrm{j}=1 \ldots \mathrm{m}$.

In general, the following formula might represent them

$$
\left\{L_{S}\right\}=\left\{L_{S}(i, j)\right\} \text { for } i=1 \ldots . n \text { and } j=1 \ldots . m
$$

The leading element has a discrete character and the unique value, while the $L_{S}(i, j)$ elements may have discrete or stochastic (probabilistic) character. If the $\mathrm{L}_{\mathrm{S}}(\mathrm{i}, \mathrm{j}$ ) elements have stochastic (probabilistic) character, the linguistic set alone might be considered to a fuzzy set the fuzzy algorithms may be applied for manipulation with the $\left\{\mathrm{L}_{\mathrm{S}}\right\}$. The linguistic variable values may have a string, numeric character. However, they may have character of relations or functions as well

$$
\mathrm{L}_{\mathrm{S}}(\mathrm{i}, \mathrm{j})<\mathrm{L}_{\mathrm{sv}} \text { or } \mathrm{LS}(\mathrm{i}, \mathrm{j})<\mathrm{f}(\mathrm{xLsv})=\mathrm{L}_{\mathrm{sv}}
$$

where

$\mathrm{L}_{\mathrm{sv}} \quad-$ is a linguistic variable value (depended variable)

$f\left(x L_{s v}\right) \quad$ - is a function, which generates $L_{s v}$ based on $\mathrm{xL}_{\mathrm{sv}}$ (in depended variable)

With respect to the above-mentioned issues, the sets $\operatorname{Petx}(i, j), P(i, j)$, Tbex (i, j'), Retx (i, j'"') Res1 (i, j'”), Res2 $(i, j$ "') and their derivatives are considered to be the linguistic sets.

Let us try analyzing the TNL sentences from semantic point of view. At first, we have to determine and describe a set of BP primary outputs or products denoted as \{Tbex (i, j")\} set. When comparing it with semantic context explanation related to the TNL sentence or sentences, which describe actual business processes the $\{$ Tbex (i, j') $\}$ set content is created by so called Terms to be explained - Tbex - terms, where $\mathrm{j} "=1 \ldots . . \mathrm{m}_{4}$ (a number of terms to be explained) contained in the i-th TNL sentence describing an actual business process. On the other hand, those terms are considered to be linguistic variables, the semantic content of which may be represented by text strings or numerical values and appropriate measure unit as well.

In order to explain, the semantic content of any TNL sentence based on the above mentioned Tbex terms; we need a set of principle terms (hereinafter known as Petx terms), which enable that explaining. However, there shall be a set of semantic rules contained within $\{P(i, j)\}$ set $j=1 \ldots m_{2}$ number of semantic rules, which enable semantic explaining of TNL sentence(s) based on Tbex terms and with the use of Petx terms. In several cases, that explaining may be supplemented by supporting terms contained within \{Retx (i, j"')\} - hereinafter known as Relating terms [11]. However, this approach to modeling of business processes in described in further published issues as well [13,16, and 17].

The equation (2.1) is denoted as: The Principle Business Process Linguistic Equation (hereinafter known as PBPL Equation). The PBPL Equation_might have adequate solution for pre-defined business processes. The first business process is postulated as: Business Strategy Creation and is considered to be the target business process. We shall have looked for an adequate solution of PBPL Equation for that business process.

\subsection{The Principle Business Process Linguistic Equation - Solutions related to answering the questions (2.1) and (2.2)}

\section{Consideration 2.2}

The equation (2.1) the Principle Business Process Linguistic Equation, which might have many solutions for different cases, while one of them is closely related to finding answer for question (2.1) and (2.2). Furthermore, let us try analyzing the business strategy goal postulated in Tab 2 and looking for the solution related to equations (2.1), (2.1a), (2.1b) and (2.1c) in order to answer the question (2.1). Let us assign adequate values to appropriate sets creating an integral part of equation (2.1) as follows:

$$
\begin{aligned}
& \mathrm{P}(\mathrm{i}, \mathrm{j})\}=\{[1],[\text { [“Turnover increase"] }\} \\
& \{\text { Tbex (i, j”) }\}=\{[1],[\text { ["five percent"] }\}
\end{aligned}
$$

$\{\operatorname{Retx}(\mathrm{i}, \mathrm{j} ")\}=\{[1]$, [weight] [“eighty"], ["percent"] $\}$

$$
\left\{\operatorname{Petx}\left(\mathrm{i}, \mathrm{j}^{\prime}\right)\right\}=\{[1],[?]\}
$$

The question mark in equation (2.3d) corresponds to question (2.2). In order to answer that question let us postulate several assumptions related to $\left\{\right.$ Petx $\left.\left(\mathrm{i}, \mathrm{j}^{\prime}\right)\right\}$ content, while five BSC perspectives should be respected. As a result of that the formulas $(2.3-2.6)$ might be valid: 


$$
\begin{aligned}
& {[\operatorname{Petx}(1,1)]=\text { "BSC Customer's Perspective" }]=} \\
= & {\left[(\operatorname{Cus}(1,1,1)),(\operatorname{Cus}(1,1,2)), \ldots .\left(\operatorname{Cus}\left(1,1, \mathrm{~m}_{1}\right)\right)\right] }
\end{aligned}
$$

where

$\left[(\operatorname{Cus}(1,1,1)),(\operatorname{Cus}(1,1,2)), \ldots .\left(\operatorname{Cus}\left(1,1, \mathrm{~m}_{1}\right)\right)\right]$ are sets closely related to individual customers (for details see also section

$$
\begin{aligned}
& {[\text { Petx }(1,1)]=\text { "BSC Internal BP Perspective" }]=} \\
= & {\left[(\operatorname{Ibp}(1,1,1)),(\operatorname{Ibp}(1,1,2)), \ldots .\left(\operatorname{Ibp}\left(1,1, \mathrm{~m}_{2}\right)\right)\right] }
\end{aligned}
$$

where

$$
\left[(\operatorname{Ibp}(1,1,1)),(\operatorname{Ibp}(1,1,2)), \ldots .\left(\operatorname{Ibp}\left(1,1, \mathrm{~m}_{2}\right)\right)\right]
$$

are sets closely related to individual internal BP running in the firm or company (for details see also section 2.5.2)

$$
\begin{aligned}
& {[\text { Petx }(1,1)]=\text { "BSC Technological Perspective" }]=} \\
= & {\left[(\operatorname{Tep}(1,1,1)),(\operatorname{Tep}(1,1,2)), \ldots .\left(\operatorname{Tep}\left(1,1, \mathrm{~m}_{3}\right)\right)\right] }
\end{aligned}
$$

where

$$
\left[(\operatorname{Tep}(1,1,1)),(\operatorname{Tep}(1,1,2)), \ldots . .\left(\operatorname{Tep}\left(1,1, \mathrm{~m}_{3}\right)\right)\right]
$$

are sets closely related to business strategy technological aspects existing in the firm or company (for details see also section 2.5.3)

$$
\begin{aligned}
& \text { [Petx }(1,1)]=\text { "BSC Learning and Growth Perspective" }]= \\
& =\left[(\operatorname{Egp}(1,1,1)),(\operatorname{Egp}(1,1,2)), \ldots .\left(\operatorname{Egp}\left(1,1, \mathrm{~m}_{4}\right)\right)\right]
\end{aligned}
$$

where

$\left[(\operatorname{Egp}(1,1,1)),(\operatorname{Egp}(1,1,2)), \ldots .\left(\operatorname{Egp}\left(1,1, \mathrm{~m}_{4}\right)\right)\right]$ are sets closely related to business strategy learning and growth aspects existing in the firm or company (for details see also section 2.5.4)

$$
\begin{aligned}
& {[\text { Petx }(1,1)]=\text { "BSC Financial Perspective" }]=} \\
= & {\left[(\operatorname{Fip}(1,1,1)),(\operatorname{Fip}(1,1,2)), \ldots .\left(\operatorname{Fip}\left(1,1, \mathrm{~m}_{5}\right)\right)\right] }
\end{aligned}
$$

where

$\left[(\operatorname{Fip}(1,1,1)),(\operatorname{Fi}(1,1,2)), \ldots .\left(\operatorname{Fip}\left(1,1, \mathrm{~m}_{5}\right)\right)\right]$ are sets closely related to business strategy technological aspects existing in the firm or company (for details see also section 2.5.5)

\subsection{Solutions for Balanced Scorecard Perspectives}

\subsubsection{Solutions related to BSC Customer's Perspective}

Let us consider a set of $\mathrm{m}_{7}$ customers who contribute to fulfillment of $\{$ Tbex $(i, j$ ') $\}=\{[1]$, ["five percent"] $\}$ value, while any of those customers contributes to the above-mentioned fulfillment by his own share, it means

$$
\text { Cus }(i, j)=\text { Cshare }(i, j)
$$

i- number of business strategy goal, $\mathrm{j}$ - number of the customer who contributes to fulfillment of $\left\{\operatorname{Tbex}\left(i, j^{\prime \prime}\right)\right\}=$ $\{[1]$, ["five percent"]\} value via his own Cshare (i, j) and sum of Cshare $(\mathrm{i}, \mathrm{j})$ covers the required $\{\operatorname{Tbex}(i, j$ ') $\}$ value(s).

$\forall$ Cus (i, j) $\exists$ Cshare (i, j) $\Rightarrow$ Cus (i, j) $=$ Cshare (i, j) $=$

$$
\{\text { Tbex (i, j'”)\} }
$$

On the other hand, let us consider a set of products $\operatorname{Pr}(i, j)$, where $(\mathrm{i}=1 \ldots \mathrm{n} 1)$ is a number of product kind and $\mathrm{j}$ is aggregated value $\quad \mathrm{Va}(\mathrm{j}, \mathrm{k})$ which represents a contribution to the customer's Cshare $(i, j)$ value

$$
\text { Cshare }(i, j)=\prod V a(j, k)
$$

where

$\mathrm{k}$ - is a number of products contained within aggregated value Va.

$\mathrm{Va}(\mathrm{j}, \mathrm{k})$ - a set of selected product kinds for appropriate share of customers Cshare (i, j) who contribute to \{Tbex ( $i$, $\left.\left.j^{\prime \prime}\right)\right\}$ value meaningful from the firm or company business strategy point of view. This is a partial answer related to the question of 2.2. What about measures from customer's point of view shall be done in order to achieve the business strategy goal predefined within Table 2?

\subsubsection{Solutions related to Internal Business Process Perspective}

Let us consider a result of PBPL general equation solution for internal business processes, which should generate outputs closely related to product types and kinds represented by $\{\mathrm{Va}(\mathrm{j}, \mathrm{k})\}$ set. On the other hand, a set of products exists, which is denoted as $\{\operatorname{Pr}(1)\}, 1=1,2 \ldots \mathrm{m} 7$, while formula (2.11) might be postulated

$$
\{\mathrm{Va}(\mathrm{j}, \mathrm{k})\} \subseteq\{\operatorname{Pr}(\mathrm{l})\}
$$

In order to assure production of products represented by $\{\mathrm{Va}(\mathrm{j}, \mathrm{k})\}$ set an appropriate set of business process running in the firm or company (hereinafter known as internal business processes Ibp) shall be operated, while they are regulated by rules with respect to equation (2.1) and formula (2.12) may be postulated:

$\forall\{\operatorname{Va}(\mathrm{j}, \mathrm{k})\} \exists\left\{\operatorname{Ibp}(\mathrm{i}, \mathrm{j}) \Rightarrow \operatorname{Petx}\left(\mathrm{i}, \mathrm{j}{ }^{\prime \prime}\right) \otimes \operatorname{Ibp}(\mathrm{i}, \mathrm{j})=\operatorname{Tbex}(\mathrm{i}\right.$, $\left.\mathrm{j}^{\prime \prime \prime}\right) \otimes \operatorname{Retx}(\mathrm{i}, \mathrm{j}, ") \& \operatorname{Tbex}\left(\mathrm{i}, \mathrm{j},{ }^{\prime \prime \prime}\right)=\{\mathrm{Va}(\mathrm{j}, \mathrm{k})\} \& \quad\{\operatorname{Retx}$

$$
(\mathrm{i}, \mathrm{j},,,,)\}
$$

where

$\mathrm{j}=1,2 \ldots . \mathrm{m} 7-$ number of product type or kind

$\mathrm{k}=1,2 \ldots \mathrm{m} 8$ - number of actual product assigned to the number of product type or kind

$\mathrm{i}=1,2 \ldots \ldots . \mathrm{n}-$ number of an appropriate internal business process Ibp

$\mathrm{j}^{\prime}=1,2 \ldots \mathrm{m} 9-$ number of function existing with internal business process Ibp

$\mathrm{j}{ }^{\prime}=1,2 \ldots \mathrm{m} 10$ products generated as a result of interaction between Ibp inputs Petx $(i, j)$ and the Ibp alone

$\mathrm{j}$ "' - index closely related to share of Ibp on the weight concerned to business strategy indicator value fulfillment

With respect to formula (2.1a) new formulas (2.13a) and (2.13b) might be postulated

$$
\begin{aligned}
& \{\text { Petx (i, j') }\} \otimes\{\operatorname{Ibp}(\mathrm{i}, \mathrm{j})\}=\left\{\operatorname{Res} 1 \mathrm{~b}\left(\mathrm{i}, \mathrm{j}^{\prime \prime}{ }^{\prime \prime}\right)\right\} \\
& \{\text { Ibpshare (i, j',' })\}=\{\operatorname{Res} 1(i, j \text { '"') }\}
\end{aligned}
$$

where 
$\{$ Ibpshare $(\mathrm{i}, \mathrm{j},,, \prime)\})$ represent a share, which contributes to $\{$ Tbex $(\mathrm{i}, \mathrm{j}, ')\}$ value meaningful from the firm or company business strategy point of view. This is a partial answer related to the question of 2.2. "What about measures from internal business processes point of view shall be done in order to achieve the business strategy goal predefined within Table 2?"

$\left\{\operatorname{Res} 1 \mathrm{~b}\left(\mathrm{i}, \mathrm{j},{ }^{\prime \prime}\right)\right\}$ - is closely related to $\operatorname{Ibp}(\mathrm{i}, \mathrm{j})$ performance and efficiency.

\subsubsection{Solutions related to Learning \& Growth perspective}

Let us consider an internal business process Ibp ( $\left.i, j^{\prime}\right)$, where $\mathrm{i}-$ is a business process (BP) number and $\mathrm{j}$ ' is a $\mathrm{BP}$ function number, the $\mathrm{BP}$ function creates the principle element of the BP structure alone. When investigating the BP function from external point of view it may be considered to be a static element with appropriate interconnections to other BP functions via inputs and outputs. However, investigating the BP function from internal point of view it should be considered to be a dynamic element with an adequate functionality and behavior regulated by set appropriate rules, while any person responsible for that business process (BP owner, BP operator or BP executor) shall be familiar with them, when fulfilling the BP operation tasks. The above-mentioned rules and other relating aspects create basis for design, implementation and operation of knowledge base, which is an integral part of the firm or company know-how as a whole. However, the knowledge, which creates base of any knowledge base, is considered to be a dynamic element from its development point of view. As a result of that, any personality responsible for business process is required to learn that development news. Therefore learning and growth plays a role of principle importance related to functionality, performance and efficiency of business processes. However, the learning and growth perspective creates an integral part of BSC System as well. In order to achieve, the above-mentioned requirements related to BP knowledge concerned to its functionality, performance and efficiency, the knowledge quantification representation plays a role of principle importance.

When looking at equation (2.1), we can see the $\left\{\right.$ Petx $\left.\left(i, j^{\prime}\right)\right\}$ set is considered to be the input set for any business process, while those inputs may be material, value or knowledge nature. With respect to issue, that the knowledge might be represented via adequate semantic networks [Sn (i, j')] [11] and reference databases $\left[\mathrm{Rd}\left(\mathrm{i}, \mathrm{j}^{\prime}\right)\right][17]$, the knowledge component of any business process input might be represented via formula (2.14a) and equation (2.1) is represented via formula $(2.14 \mathrm{~b})$

$$
\begin{aligned}
& \left\{\text { Petx }\left(i, j^{\prime}\right)\right\} \otimes\{P(i, j)\}=\left\{\text { Tbex }\left(i, j{ }^{\prime}\right)\right\} \otimes\{\operatorname{Retx}(i, \\
& \text { j"')\} } \\
& \left\{\text { Petx }\left(i, j^{\prime}\right)\right\}=\left\{[\text { Sn (i, j') }],\left[R d\left(i, j^{\prime}\right)\right]\right\}
\end{aligned}
$$

This is an outgoing equation, when looking for an answer to question, "What about measures from learning and growth point of view shall be done in order to achieve the business strategy goal predefined within Table 2?"

When looking at equation $(2.14 \mathrm{~b})$, we can see a set of semantic networks [Sn $\left.\left(i, j^{\prime}\right)\right]$, which represent know-how held in heads of personalities responsible for business process operation and the set of BP rules and regulations related to BP functionality, performance and efficiency postulated within appropriate norms and standards.

Let us try applying equation (2.1b) in order to determine a share of knowledge concerned to BP functionality, performance and efficiency relating to fulfillment of $\{$ Tbex ( $i$, $\left.\left.j^{\prime \prime}\right)\right\}=\{[1]$, ["five percent"] $\}$ (see also Table 2) and let us suppose, the above mentioned knowledge is closely related to BSC Learning and Growth perspective and the knowledge represent input for $\mathrm{BP} \quad\{\mathrm{P}(\mathrm{i}, \mathrm{j})\}$ functionality. With respect to those assumptions equation (2.1b) might be represented via formula $(2.15)$

$$
\{\text { Petx (i, j') }\} \otimes\{P(i, j)\}=\operatorname{Res} 1 \text { eg }\left(i, j^{\prime \prime}\right)
$$

With respect to equation $(2.14 b)$ the equation (2.15) may be converted into equation (2.16)

$$
\left\{\left[\operatorname{Sn}\left(i, j^{\prime}\right)\right],\left[R d\left(i, j^{\prime}\right)\right]\right\} \otimes\{P(i, j)\}=\operatorname{Res} 1 \text { eg }\left(i, j^{\prime \prime}\right)
$$

and a share of knowledge concerned to BP functionality, performance and efficiency relating to fulfillment of $\{$ Tbex $(i$, $j, ')\}=\{[1]$, ["five percent"] $\}$ Egshare might be described via formula (2.17)

$$
\text { Egshare (i, j') = Res1eg (i, j'”) }
$$

However, this is qualitative view to share of knowledge related to fulfillment of $\{$ Tbex $(i, j$ '” $)\}=\{[1]$, ["five percent"]\}. A quantitative view to that problem is over the paper range and will not be discussed here. A reader is kindly recommended to consult book [13].

\subsubsection{Solutions related to Technological Perspective}

The BSC Technological perspective represents a selected set of relations closely related to BSC Learning and Growth perspective, which might be implemented and operated within actual firm or company with respect to uncertainty and risk. This uncertainty might be represented with the use fuzzy set apparatus and the risk may be represented with the use of probabilities.

The above-mentioned problem is being solved based on fuzzy logic, which enables accepting of uncertainty, inaccuracy and vague aspects and provides a simple way for working with semantic meaning of words written in a natural language. When considering this approach, the BSC Technological Perspective is the fuzzy model, which contains a set of appropriate linguistic variables [5]. Let's have a look at that model functionality.

Technological Perspective contribution is a conversion of business strategy goals towards the firm or company customers and internal business processes running there (see also Fig. 1). The Technological Perspective, which is closely related to Learning and Growth Perspective and represents a decisive factor affecting the firm or company market value. 


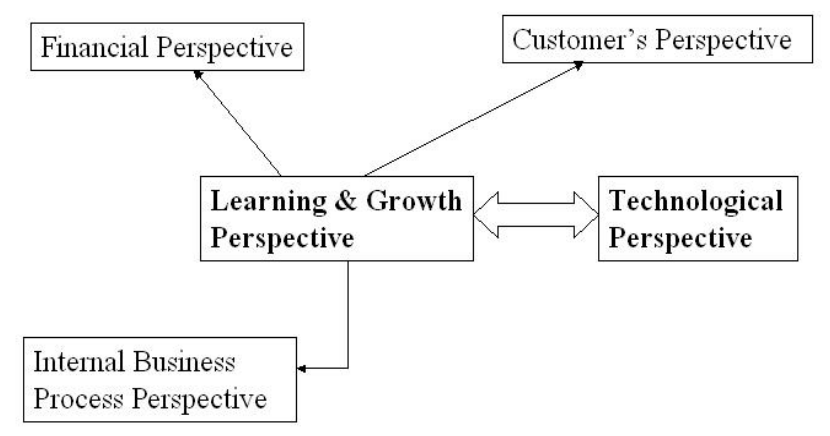

Figure 1. Technological Perspective as an extension of Learning and Growth Perspective

The firm or company market value concept deals with an opinion concerned to market firm or company benefits and prosperity in an appropriate time. However, a determination of the firm or company market value is considered to be a complicated and complex problem, where a set of appropriate methods is applied, while the methods are categorized with respect to factors affecting the final value and methods of the final value computation as well.

However, when considering a relation between goodwill and BSC Learning and Growth Perspective, the industrial goodwill plays a role of principle importance, while this type of goodwill includes the firm or company technological equipment, employment stability and satisfaction of employees too. First of all, we are interesting in the position and tasks of BSC Technological Perspective, which represents a selected set of relations dealing with Learning and Growth Perspective, while an appropriate uncertainty and risk measure is observed, when implementing and operating those relations via real business processes running within actual firm or company. However, the above-mentioned uncertainty might be quantified via fuzzy set apparatus and an appropriate set of probabilistic algorithms might be applied in order to quantify the above-mentioned risk aspects as well.

We are doing best to find a solution for uncertainty problem with the use of fuzzy logic, which enables accepting of uncertainty and vagueness and working with semantic content of TNL words. With respect to this issue, the Technological Perspective is considered to be a fuzzy model containing linguistic variables.

With respect to above-mentioned issues, the knowledge closely related to BP functionality might be divided in two groups:

\{A\} Terms and principles related BP unit functionality and BP functionality as a whole, incl. required outputs and corresponding inputs.

\{B $\}$ BP controlling terms and principles related to BP outputs and business indicators strategy indicators - key performances indicators valid for the firm or company where those business processes running.

This section deals with qualitative aspects (terms, principles and issues) related to BSC Technological Perspective, while the quantitative aspects of PBPL Equation solution for that type of BSC perspective are described in Section 3.3.

\section{How the Principle Business Process Linguistic Equation (PBPL Equation) may be Applied in Solution of Business Strategy Design and Business Process Management Problems - Business}

Ontology is a "formal, explicit specification of a shared conceptualization" as defined by [18]. In our proposal, ontology is used for asserting statements about knowledge represented by PBL equation, the solution of which is closely related to BSC system application for preparing of business strategy within actual firm or company. In general, adding ontology has several advantages: enables a flexible representation of the inference rules and the knowledge, reduces human intervention in maintenance, allows an automatic verification of data consistency, promotes modularity and enhances scalability and future reuse. Accordingly, they are appropriate to fulfill these requirements [2].

\subsection{The PBPL Equation Solution for BSC Customer's and Internal Business Process Perspective}

The aim of PBPL equation ontology is to represent the variables contained in that equation as well as linguistic labels, which can be associated to each of them. The PBPL Equation contains four types of variables $\{$ Petx $(i, j)\},\{P(i$, $\left.\left.\left.j^{\prime}\right)\right\}\right\},\{$ Tbex (i,j") $\}$ and $\{\operatorname{Retx}(i, j$ ' $)\}$ and have a fuzzy set nature. Any of the above-mentioned types of variables having a fuzzy set nature contain appropriate linguistic variable items and linguistic variable values. The $\{\operatorname{Petx}(\mathrm{i}, \mathrm{j})\}$ linguistic variable items and vales are closely related to material, valuable and knowledge (information) business process inputs, while the index $\mathrm{j}$ indicates the relation to material $(j=1)$, valuable $(j=2)$ and knowledge (information) $(j=3)$ and the index $i$ indicates a number of business process which the input variable $\{$ Petx $(i, j)\}$ is concerned to. The variables $\left.\left\{P\left(i, j^{\prime}\right)\right\}\right\}$ linguistic variable items and vales are closely related to business process vertical and horizontal structure. When considering the business process vertical structure, $\mathrm{i}$ index indicates the business process position within hierarchy of supervisory business processes. When considering the business process (BP) horizontal structure, i index indicates a linguistic (semantic) interconnection between $\{$ Petx $(i, j)\}$ and $\left.\left\{P\left(i, j^{\prime}\right)\right\}\right\}$ variables. On the other hand, the $\mathrm{j}$ index indicates a number of BP function with an appropriate linguistic (semantic) content, while $j=1 \ldots . \mathrm{m}$ ' and $\mathrm{m}$ means a number of functions, which the actual business process consists of. When considering a linguistic approach to BP modeling with the use of fuzzy set apparatus, the above-mentioned functions might be 
represented by a trapezoidal function. When executing operation with respect to formula (3.1)

$$
\left.\{\text { Petx }(i, j)\} \otimes\left\{P\left(i, j^{\prime}\right)\right\}\right\}=\operatorname{Res} 1\left(i, j_{x}\right)
$$

When applying that formula to preparing business strategy with respect to customer's and internal business process perspective, that formula might enable answering the question: "what about strategic aims shall be postulated and fulfilled in order satisfy the customer's requirements.

Let us consider a fuzzy set $\{$ Cus $(i, j)\}$, which contains linguistic variable items, linguistic variable item values and concerned to customers and their requirements e.g. products (articles) or services and a set Ibp (i, j') which contains linguistic variable items and linguistic variable item value concerned to internal BP running within firm or company, the linguistic operation (3.1) can be transformed into formula (3.2a and $3.2 \mathrm{~b}$ )

$$
\begin{gathered}
\{\text { Cus }(i, j)\} \otimes\left\{\operatorname{Ibp}\left(i, j^{\prime}\right)\right\}=\operatorname{Res} 1\left(i, j_{\mathrm{x}}\right) \\
\left\{\text { Sg }\left(i, j_{\mathrm{x}}\right)\right\}=\left\{\operatorname{Res} 1\left(i, j_{\mathrm{x}}\right)\right\}
\end{gathered}
$$

$\left\{\operatorname{Sg}\left(i, j_{\mathrm{x}}\right)\right\}$ is the set, which contains elements concerned to a question "What about strategic aims shall be postulated and fulfilled in order satisfy the customer's requirements". However, the set $\{$ Cus $(i, j)\}$ is closely related to BSC Customer's perspective and $\left\{\operatorname{Ibp}\left(i, j^{\prime}\right)\right\}$ is closely related to BSC internal business process perspective and the $\left\{\operatorname{Sg}\left(i, j_{x}\right)\right\}$ set contains elements closely related to answering the above-mentioned question, while the $\left\{\operatorname{Sg}\left(i, j_{\mathrm{x}}\right)\right\}$ creates an integral part of the BSC system as well.

With respect to the above-mentioned facts formulas (3.2a) and (3.2b) represent the PBPL Equation for BSC customer's and internal business process perspective

\subsection{The PBPL Equation Solution for BSC Internal Business Process Perspective and Learning and Growth Perspective}

Let us have a look at business process functionality and treatment from knowledge need point of view.

On one hand, any business process (BP) consists of several functional units providing appropriate functionalities. On the other hand and BP function generates a set of pre-defined outputs and requires adequate inputs for those purposes. Usually, the BP consists of more than one functional unites ${ }^{4}$. In general, any BP functional unit consists of appropriate functional elements providing pre-defined operations aimed to achievement of appropriate outputs. As mentioned above, a set of appropriate inputs are needed for these purposes. In order to assure a proper functionality of BP containing more functional units a set of appropriate interfaces shall be standing among them. With respect to above-mentioned issues, the knowledge closely related to BP functionality might be divided in two groups:

$\{$ A $\}$ Terms and principles related BP unit functionality

4 There may exist a business process, which contains only one functional unit, however it occur in a very few cases actually and BP functionality as a whole, incl. required outputs and corresponding inputs.

\{B $\}$ BP controlling terms and principles related to BP outputs and business indicators strategy indicators - key performances indicators valid for the firm or company where those business processes running.

This knowledge types create knowledge base fundamentals, while that knowledge base creates an integral part of ontology related to the above-mentioned business processes.

Let us consider equation (3.1) and further two ones postulated via formulas

$$
\begin{gathered}
\left\{\operatorname{Res} 2\left(\mathrm{i}, \mathrm{j}_{\mathrm{x}}\right)\right\}=\left\{\operatorname{Tbex}\left(\mathrm{i}, \mathrm{j}^{\prime \prime}\right)\right\} \otimes\left\{\operatorname{Retx}\left(\mathrm{i}, \mathrm{j}{ }^{\prime \prime}\right)\right. \\
\left\{\operatorname{Res} 2\left(\mathrm{i}, \mathrm{j}_{\mathrm{x}}\right)\right\}=\left\{\operatorname{Res} 1\left(\mathrm{i}, \mathrm{j}_{\mathrm{x}}\right)\right\}
\end{gathered}
$$

where

$\{$ Tbex $(\mathrm{i}, \mathrm{j}$ ') $\}$ - is a set of BP outputs, which affect the KPI values directly

$\{$ Retx $(\mathrm{i}, \mathrm{j}, ")\}$ - is set of primary $^{5}$ and secondary ${ }^{6}$ knowledge, which affect the $\{$ Tbex $(i, j$ ' $)\}$ set content directly

When considering formulas (3.1), (3.3a) and (3.3b), the following questions might be postulated:

\section{Question no.1}

"How the $\{A\}$ and $\{B\}$ knowledge set is affecting a set of BP outputs (linguistic item values) contained within $\{$ Tbex ( $i$, j') \} set and a fulfillment of KPI values subsequently.

\section{Question no.2}

"How the $\{A\}$ knowledge and $\{B\}$ set is affecting a set of primary and secondary knowledge creating the $\square$ Retx (i, j'")\} content?"

With respect to the above-mentioned questions formulas (3.4a) and (3.4b) might be postulated:

$$
\begin{aligned}
& \{A\} \otimes\left\{\operatorname{Ibp}\left(i, j^{\prime}\right)\right\}=\operatorname{Res} 1(i, j x) \\
& \{B\} \otimes\left\{\operatorname{Ibp}\left(i, j^{\prime}\right)\right\}=\operatorname{Res} 2(i, j x)
\end{aligned}
$$

and formulas (3.3a) and (3.3b) are valid as well, while formulas (3.4a) and (3.4b) together with formulas (3.7.3a) and (3.7.3b) represent a solution of PBPL equation for BSC Learning and Growth perspective.

\subsection{The PBPL Equation Solution for BSC Internal Business Process Perspective and Technological Perspective}

In order to specify the knowledge base closely related to BP functionality as postulated within Section 3.2 let us consider a set of business processes $\{\operatorname{Ibp}(\mathrm{i}, \mathrm{j})\}$, which should

5 The term "Primary knowledge" means a set of new knowledge generated as a result of BP Ibp (i, j) acting to set of inputs denoted as Petx $(\mathrm{i}, \mathrm{j})$

6 The term "Secondary knowledge" means a set of existing knowledge closely related to BP running with respect to formula (3.1). However, the primary knowledge becomes the secondary, when applying it for other BP, appear or situation and is being modified for those purposes. 
generate primary outputs represented, by $\{$ Tbex $(\mathrm{i}, \mathrm{j}$ ') $\}$ set and secondary outputs represented by $\left\{\operatorname{Retx}\left(\mathrm{i}, \mathrm{j},{ }^{\prime \prime}\right)\right\}$ set with the use of inputs represented by $\left\{\right.$ Petx $\left.\left(i, j^{\prime}\right)\right\}$, while equation (2.1) is valid, in general. On the other hand, there is a general rule that no business process is able to operate properly and efficiently without adequate technological, information and knowledge support. The same is concerned to business process running within management on strategic level and within business strategy creation as well. However, any business process a running behaviour of which is regulated via equation (2.1) generates material, valuable, information or knowledge outputs too. Let us have a look at those aspects in more details.

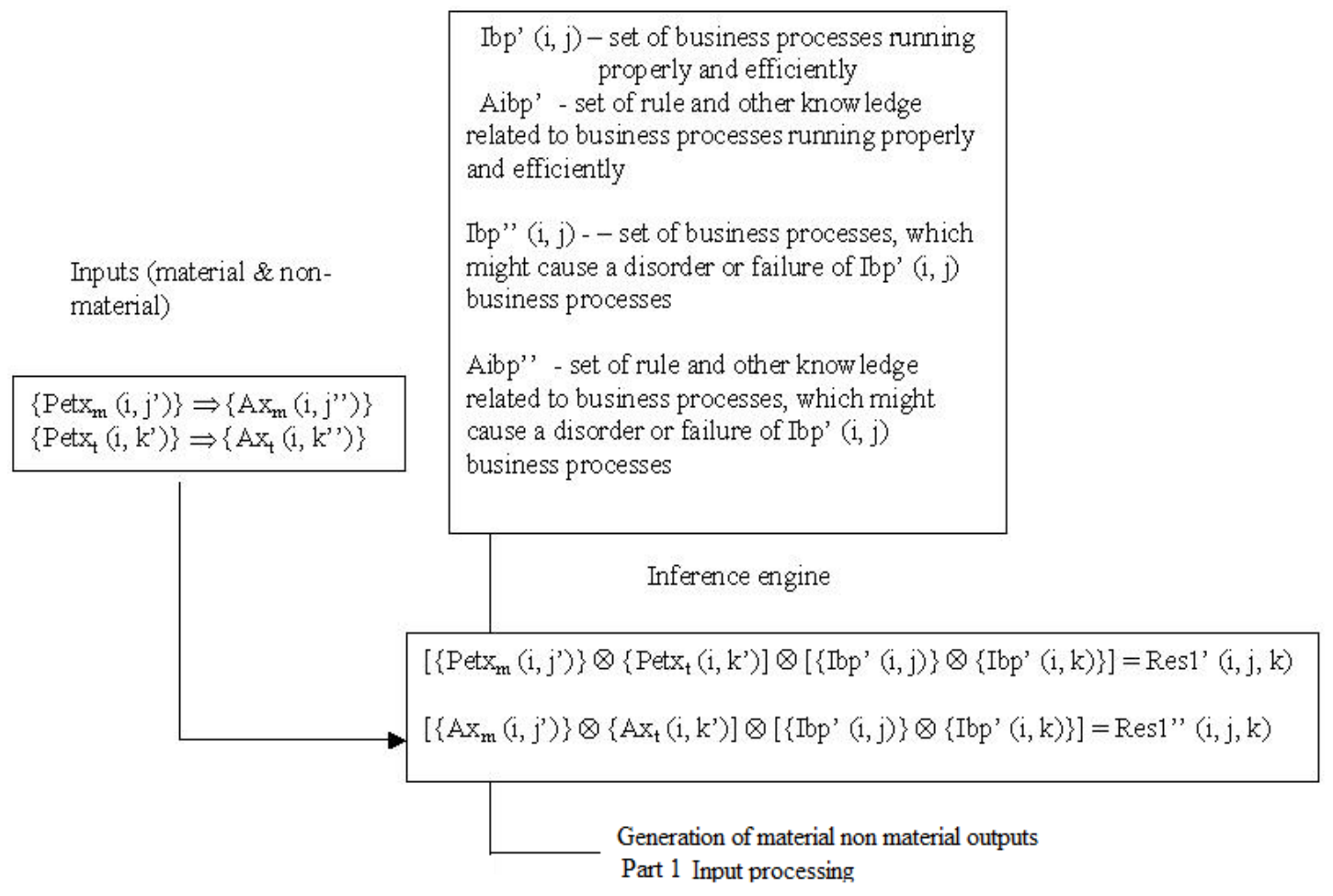

Material outputs, which correspond to quality requirements

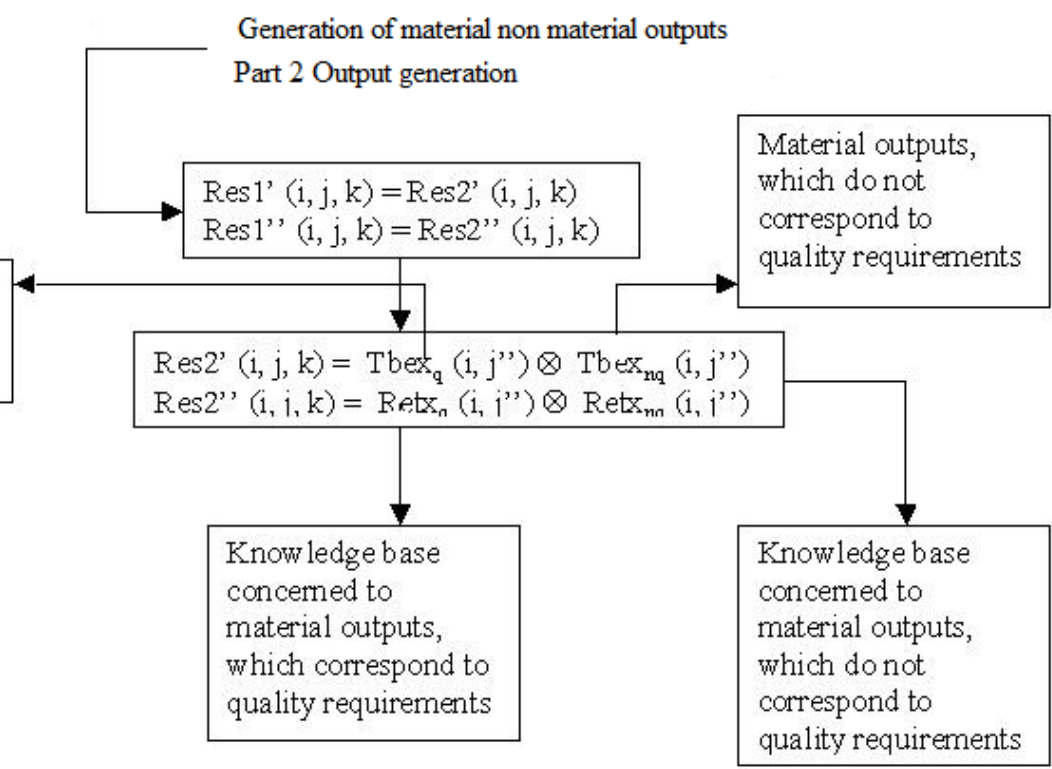

Figure 2. Model, which represents a solution of PBPL Equation for BSC Technological Perspective (Part 1, Part 2) 
Now, let us try applying formula (3.5) related to solution of PBPL equation (see also formula (2.1) and formula (2.1a2.1.c) for BSC technological perspective. When looking at PBPL equation (formula 2.1), we can see that $\{$ Tbex (i,j")\} linguistic set elements represent the primary output (product) parameters ${ }^{7}$, while $\{$ Retx (i, j”') $\}$ linguistic set elements represent the secondary output (product) parameters ${ }^{8}$.

$$
<\mathrm{x}, \mathrm{T}(\mathrm{x}), \mathrm{U}, \mathrm{G}, \mathrm{M}>
$$

where

$\mathrm{x}-$ is the linguistic variable name

$\mathrm{T}(\mathrm{x})$ - is the set of values related to the linguistic variable name

$\mathrm{U}$ - universum, which represents a meaning of any expression contained in $\mathrm{T}(\mathrm{x})$

$\mathrm{G}$ - syntactic rule applied for generation of new linguistic terms and expressions

M- semantic rule assigning affiliation function for each linguistic expression $\mathrm{T}(\mathrm{x})$

With respect to formula (2.1) and formulas (2.1a- 21.c) formula (3.5) might be converted into formulas (3.6a up to 3.6d)

$$
\begin{aligned}
& \mathrm{x}=\left\{\operatorname{Res} 2\left(\mathrm{i}, \mathrm{j},{ }^{\prime \prime \prime}\right)\right\} \\
& T(X)=\{\operatorname{Tbex}(i, j ')\} \otimes\{\operatorname{Retx}(i, j ” ')\} \\
& \mathrm{G}=\left\{\operatorname{Petx}\left(\mathrm{i}, \mathrm{j}^{\prime}\right)\right\} \otimes\{\mathrm{P}(\mathrm{i}, \mathrm{j})\}=\left\{\operatorname{Res} 1\left(\mathrm{i}, \mathrm{j}^{\prime}{ }^{\prime \prime}\right)\right\} \\
& \mathrm{M}=\left\{\operatorname{Res} 1\left(\mathrm{i}, \mathrm{j}{ }^{\prime \prime \prime}\right)\right\}=\left\{\operatorname{Res} 2\left(\mathrm{i}, \mathrm{j}{ }^{\prime \prime}\right)\right\}
\end{aligned}
$$

As mentioned above, any business process is running in order to generate outputs, which enable fulfillment a content of business strategy indicators. These outputs might be of material $\{$ Tbex (i, j") $\}$ and non-material nature $\{$ Retx (i, $\mathrm{j}$ "') $\}$. On the other hand, no business process is able to generate required outputs without appropriate inputs, which might be of material $\{$ Petx (i, j') $\}$ and non-material [ $\{$ Ax (i, $\left.j^{\prime}\right)$ \} nature as well. When considering the BSC Technological Perspective the above-mentioned material inputs $\left\{\operatorname{Petx}\left(i, j^{\prime}\right)\right\}$ consist of input materials $\left\{\operatorname{Petx}_{\mathrm{m}}\left(\mathrm{i}, \mathrm{j}^{\prime}\right)\right\}$ getting in the business process $\{\operatorname{Ibp}(\mathrm{i}, \mathrm{j})\}$ directly and technological devices $\left\{\right.$ Petx $\left._{\mathrm{t}}\left(\mathrm{i}, \mathrm{k}^{\prime}\right)\right]$, which create an integral part of an appropriate business process or processes and enable converting input materials $\left\{\operatorname{Petx}_{\mathrm{m}}\left(\mathrm{i}, \mathrm{j}^{\prime}\right)\right\}$ into required outputs. However, no business process functionality is possible without adequate knowledge (information) support as well. As a result of that, a set of non-material inputs (knowledge and information) play a role of principal importance, when operating business processes. They might be divided in two categories, knowledge and information concerned to input materials $\left\{\operatorname{Petx}_{\mathrm{m}}\left(\mathrm{i}, \mathrm{j}^{\prime}\right)\right\}$ denoted as $\left\{\mathrm{Ax}_{\mathrm{m}}\right.$ $\left.\left(i, j^{\prime}\right)\right\}$ and knowledge and information concerned to

7 The primary outputs generated as a result of Ibp business process functionality usually might have material nature

8 The secondary outputs generated as a result of Ibp business process functionality usually might have n0n-material nature appropriate technological devices $\left\{\mathrm{Ax}_{\mathrm{t}}\left(\mathrm{i}, \mathrm{k}^{\prime}\right)\right]$.

In general, a set of required outputs is generated via interaction between business process and adequate material and non-material inputs (see also formula 2.1a), while an intermediate product $\{\operatorname{Res} 1(\mathrm{i}, \mathrm{j}, ")\}$ is being created. However, there is running a set of business processes operating properly and efficiently denoted as Ibp' $(i, j)$ and a set of business processes, which might cause a disorder or failure of Ibp' ( $i, j$ ) business processes (denoted as Ibp' (i, j) processes) might start running as well. This aspect is concerned to both, material and non-material input materials (resources) and plays a role of great importance within BSC Technological

Perspective. With respect to the above-mentioned issues formula (2.1a) may be transformed in two appropriate formulas (3.7a and 3.7b), which create basis of inference engine_(see also Fig.2), where the reader may find more detailed explanation concerned to equations (3.7a) and (3.7b).

$$
\begin{array}{r}
{\left[\{ \operatorname { P e t x } _ { \mathrm { m } } ( \mathrm { i } , \mathrm { j } ^ { \prime } ) \} \otimes \{ \operatorname { P e t x } _ { \mathrm { t } } ( \mathrm { i } , \mathrm { k } ^ { \prime } ) ] \otimes \left[\left\{\mathrm{Ibp}^{\prime}(\mathrm{i}, \mathrm{j})\right\} \otimes\{\mathrm{Ibp}\right.\right.} \\
(\mathrm{i}, \mathrm{k})\}]=\operatorname{Res} 1^{\prime}(\mathrm{i}, \mathrm{j}, \mathrm{k}) \\
{\left[\{ \mathrm { Ax } _ { \mathrm { m } } ( \mathrm { i } , \mathrm { j } ^ { \prime } ) \} \otimes \{ \mathrm { Ax } _ { \mathrm { t } } ( \mathrm { i } , \mathrm { k } ^ { \prime } ) ] \otimes \left[\left\{\mathrm{Ibp}^{\prime}(\mathrm{i}, \mathrm{j})\right\} \otimes\{\mathrm{Ibp})\right.\right.} \\
\mathrm{k})\}]=\operatorname{Res} 1^{\prime \prime}(\mathrm{i}, \mathrm{i}, \mathrm{j}, \mathrm{k})
\end{array}
$$

Subsequently, an intermediate product $\{\operatorname{Res} 1(\mathrm{i}, \mathrm{j}, ")\}$ is being transformed to further intermediate product $\{$ Res2 (i, j"') $\}$, which enables generating of primary and secondary outputs, which might be of material and non-material nature as well (see also formulas (3.8a) and (3.8b) and Fig.2 for more details).

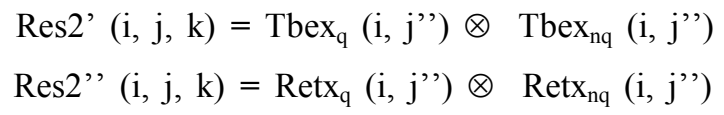

When looking at Fig.2, we can see two types of output primary and secondary products:

Outputs, which correspond to quality requirements

Outputs, which do not correspond to quality requirements

The above-mentioned formulas and equations and descriptions represent a solution of PBPL Equation for BSC Technological Perspective.

\section{Contributions of the Paper Content}

This contribution/paper deals with theoretical and conceptual aspects of BSC perspective linguistic modeling. In order to introduce the knowledge contained in that paper in practice a set of different auxiliary variables should be determined, which should be applied, when implementing and operating adequate application programs environment of Jess programming language ${ }^{9}$. Those aspects are considered to be outside the paper range and are not discussed in that paper.

\footnotetext{
9 Jess - Rule Engine for Java Platform http://herzberg.ca.sandia.gov/jess/
} 


\subsection{Contributions within Scientific Practice}

We can say that business process management provided on strategic, tactic and operational level is often characterized by fuzziness. This term means that the decision premises are not available in the form of mathematic models or numeric values, but rather as fuzzy conditions. As a result of that an adequate mathematic apparatus shall be applied for those fuzziness representation purposes, which is based on a set of linguistic variables and fuzzy sets as well. This paper deals with algorithms, where the above-mentioned linguistic variables and fuzzy sets are being applied in order to describe strategy goal indicators versus core, support and management business process views, which is considered to be the main contribution of that paper within scientific practice

\subsection{Contributions within Educational Practice}

This paper contains information, which might be applied, when preparing teaching plans related to business process management and business strategy creation problems, while those aspects are closely related to management course accredited and taught within many high schools and universities.

\subsection{Contributions within Social Practice}

In principle, any business is getting started via mission statement and objective definition, which create basis for business strategy definition as well, while the business strategy aspects are being postulated in a verbal form (text in natural language $-\mathrm{TNL}$ and in form of critical performance indicators (KPI -indicators).

On the other hand, a set of appropriate target and main business processes shall be defined, which enable fulfilment of business strategy goals or aims postulated via TNL sentences or KPI indicators. Both, the business strategy goals and the target or main business process may be represented by set of adequate TNL sentences or graphs. In order to, understand business strategy goal and target or main process quintessence, an appropriate text semantic analysis should be done. The text semantic analysis results could show us how the above-mentioned target and main process should operate in order to assure a fulfilment of business strategy qualitative and quantitative indicators. This paper deals with a set of such algorithms especially and create basis for design and implementation of adequate application programs, which may be applied when creating the business strategy outlines. This is the main contribution of that paper content.

\section{Conclusions}

This paper proposes business strategy design in form of text written in a natural language and in form of linguistic sets, which contain appropriate linguistic variables and postulates the principle business process linguistic equation PBPL equation incl. assumptions, terms and principles related to its existence and functionality. On the other hand, this paper contains two principle questions closely related to business strategy design, which might be applied within any firm or company. In order to answer those questions, a set of adequate PBPL Equation should be looked for related to appropriate BSC perspectives. However, the PBPL Equation may be applied in solution of business strategy design and business process management problems with respect business process ontology aspects, where four questions postulated within Section 3.2 play a role of great importance aspects contained there require adequate solution and quantification. However, this fact creates basis for further development PBPL Equation as well, especially related to BSC Learning and Growth and Technological Perspective together with determination of appropriate auxiliary variable values for individual BSC perspectives.

\section{REFERENCES}

[1] Amy H.I. Lee, Wen-Chin Chen , Ching-Jan Chang: A fuzzy AHP and BSC approach for evaluating performance of IT department in the manufacturing industry in Taiwan expert systems with applications 34 (2008) 96-107 http://lc2.fotech.edu.tw/leerefpapers/dropbox/pdf/0705perfor mace-evaluation $/ 000$-a $\% 20$ fuzzy $\% 20$ ahp $\% 20$ and $\% 20 \mathrm{bsc} \% 2$ 0approach $\% 20$ for $\% 20$ evaluating $\% 20$ performance $\% 20$ of $\% 2$ 0it\%20department $\% 20$ in $\% 20$ the $\% 20$ manufacturing $\% 20$ indu stry\%20in\%20taiwan.pdf

[2] Bobillo, F.- Delgado, M.- Gómez-Romero, J.- López, E.: Introducing semantics and vagueness in a balanced scorecard http://decsai.ugr.es/ jgomez/docs/ciic07\%20\%20introducing $\% 20$ semantics\%20and\%20vagueness.pdf

[3] Calabrese, Armando, Costa, R, M.: Expert systems with applications Volume: 40 Issue: 9 Pages: 3747-3755 Published: July, 2013, CCC:000316581300038, ISSN: $0957-4174$

[4] Colan, M.: Fuzzy or linguistic input scorecard for IPR evaluation, Journal of applied operational research (2013) 5(1), 22-29, ISSN 1735-8523 (print), ISSN 1927-0089 (online)

http://www.tadbir.ca/jaor/archive/v5/n1/jaorv5n1p22.pdf

[5] Grell, M. - Stašák, J.: Metodické základy sémantického prístupu $\mathrm{v}$ systéme Balanced Scorecard. In Ekonomika a manažment : Vedecký časopis Fakulty podnikového manažmentu Ekonomickej univerzity $\mathrm{v}$ Bratislave. Bratislava : Fakulta podnikového manažmentu Ekonomickej univerzity v Bratislave, 2011. ISSN 1336-3301, 2011, Roč. 8, č. 2, s. 34-46. VEGA 10261/10.

[6] Hacklin, F.- Wallnoefer, M.: Management decision Volume: 50 Issue: 1-2 pages: 166-188 Published: 2012, CCC:000303029000011, ISSN: 0025-1747

[7] (Kao, C. - Liu, St.: Operations research applications in Taiwan: a linguistic approach European Journal of Operational Research Volume: 103 Issue: 3 pages: 628-634 
Doi: 10.1016/s0377-2217 (97) 00145-8 Published: Dec 16 1997

[8] (Lin, Ging-Lian, Liu, Long, Liu, Hu-Chen, Wang, Duo-Jin: Expert Systems with Applications Volume 40 Issue: 6 Pages: 1917-1924 Published: May 2013, CCC:000315607200001, ISSN: 0957-4174

[9] Manian, A.- Fathi, M.R.- Zarchi, M.K.-Omidian, A. : Performance Evaluating of IT Department Using a Modified Fuzzy TOPSIS and BSC Methodology (Case study: Tehran Province Gas Company) Journal of management research 2011, Vol. 3, No. 2: E10, ISSN 1941-899X

[10] Shaverdi, M.- Akbari, M.- Tafti, S.F.: Combining Fuzzy MCDM with BSC Approach in Performance Evaluation of Iranian Private Banking Sector http://www.hindawi.com/jour nals/afs/2011/148712

[11] Stašák, J., 2004: A contribution to semantic text analysis in: electronic computers and informatics ECI 2004, The University of Technology Košice, Department of computers and informatics of FEI, 22-24. 9.2004 Košice - Herlany, SR, p.132-144, ISBN 80-8073-150-0

[12] Stašák, J. , 2007: Representation of interfaces via fuzzy sets apparatus, management information systems, 2007, ISSN $1452-774 \times$ p. $47-53$

[13] Stašák, J.: Princípy modelovania ekonomických objektov (Basic principles of economic object modeling) Ekonom, Bratislava, 2010

[14] Stašák, J.: Modelovanie procesov podnikania s využitím aplikačného programu ARIS, (Business process modeling based on system ARIS applications (Part I. Business process analysis and design), Ekonóm, Bratislava, 2010.
[15] Stašák, J.:Lingvistický prístup ku kvantifikácii a modelovaniu biznis procesov (Linguistic approach to business process quantification and modeling), In vybrané problémy hospodárskej informatiky : monografický zborník vedeckých statí recenzovaný, nekonferenčný, zameraný na problémy hospodárskej informatiky [Elektronický zdroj]. Bratislava: Vydavatel'stvo Ekonóm, 2010. ISBN 978-80-225 $3110-8$, s. 187-201.

[16] Stašák, J.: How image and text semantic analysis systems may be applied for educational and teaching purposes - Acta technologica dubnicae, 2011, No.1, and p.1-18, ISSN $1338-3965$

[17] Stašák, J.: Business process quantification and modeling linguistic approach - several theoretical aspects American international journal of contemporary research (AIJCR) 2012, no.4, p. 85-100, ISSN 2162-139x

[18] Studer, V. R. Benjamins, D. Fensel. Knowledge Engineering: Principles and Methods Data Knowledge Engineering 25 (1-2), 161-197, 1998.

[19] Thomas, O. - Dollmann, T. - Loos, P., 2007) towards enhanced business process models based on fuzzy attributes and rules www.sigpam.org/wp-content/uploads/2007/08/oliver.pdf

[20] Volkner, P. - Werners, B.: A simulation-based decision support system for business process planning. Fuzzy sets and systems volume: 125 Issue: 3 Pages: 275-287 Doi: 10.1016/s0165-0114 (00) 00105-6 published: Feb 1 2002, CCC:000173284200001, ISSN: 0165-0114

[21] Yuksel, I, Dagdeviren, M., 2010) Expert systems with applications Volume: 37 Issue: 2 Pages: 1270-1278 Published: mar 2010, CCC:000272432300046, ISSN: 0957-4174 